\title{
Model Pembelajaran WEE Ditinjau dari Curiosity: Pengaruhnya terhadap Kemampuan Pemahaman Konsep Matematis
}

\author{
Ulfa Iqoh $^{\left.1^{*}\right)}$, Achi Rinaldi ${ }^{2}$, \& Rizki Wahyu Yunian Putra ${ }^{3}$ \\ 1, 2, 3 Universitas Islam Negeri Raden Intan Lampung, Bandar Lampung, Indonesia
}

\section{INFO ARTICLES}

Article History:

Received: 21-06-2021

Revised: 30-06-2021

Approved: 30-06-2021

Publish Online: 30-06-2021

\section{Key Words:}

WEE; Curiosity; Ability;

Mathematical Concepts;

\begin{abstract}
The achievement of students in mathematics is still relatively low, so an appropriate learning model is needed in the learning process. The purpose of this study was to determine the effect of the WEE learning model in terms of Curiosity on the ability to understand students' mathematical concepts. This research is a Quasi Experimental Design research type. Sampling was carried out using the Cluster Random Sampling technique. Data collection techniques using tests, questionnaires and documentation. Hypothesis testing using two-way ANOVA (Analysis of Variance) test of unequal cells with a significance level of 5\%. Based on the results of the study, it was concluded that there was an effect of the WEE learning model in terms of Curiosity on the ability to understand students' mathematical concepts.
\end{abstract}

\begin{abstract}
Abstrak: Prestasi peserta didik pada mata pelajaran matematika masih relatif rendah sehingga dibutuhkan model pembelajaran yang tepat dalam proses pembelajaran. Tujuan dari penelitian ini untuk mengetahui pengaruh dari model pembelajaran WEE ditinjau dari Curiosity terhadap kemampuan pemahaman konsep matematis peserta didik. Penelitian ini termasuk jenis penelitian Quasi Eksperimental Design. Pengambilan sampel dilakukan menggunakan teknik Cluster Random Sampling. Teknik pengumpulan data menggunakan tes, angket dan dokumentasi. Pengujian hipotesis menggunakan uji anova (Analysis of Variance) dua arah sel tak sama dengan taraf signifikasi 5\%. Berdasarkan hasil penelitian, diperoleh kesimpulan bahwa terdapat pengaruh model pembelajaran WEE ditinjau dari Curiosity terhadap kemampuan pemahaman konsep matematis peserta didik.
\end{abstract}

Correspondence Address: Jln. Pulau Sebesi, Gang Budaya, Kec. Sukarame, Kota Bandar Lampung, 35131, Indonesia; e-mail: ulfa.iqoh3107@gmail.com

How to Cite (APA $6^{\text {th }}$ Style): Iqoh, U., Rinaldi, A., \& Putra, R.W.Y. (2021). Model Pembelajaran WEE Ditinjau dari Curiosity: Pengaruhnya terhadap Kemampuan Pemahaman Konsep Matematis. JKPM (Jurnal Kajian Pendidikan Matematika), 6(2): 267-278

Copyright: 2021 Ulfa Iqoh, Achi Rinaldi, Rizki Wahyu Yunian Putra

Competing Interests Disclosures: The authors declare that they have no significant competing financial, professional or personal interests that might have influenced the performance or presentation of the work described in this manuscript. 


\section{PENDAHULUAN}

Pendidikan merupakan salah satu kebutuhan manusia yang sangat penting guna menentukan maju mundurnya suatu bangsa. Menurut UU No. 20 Tahun 2003 (Indonesia, 2003) menjelaskan bahwa pendidikan adalah usaha sadar dan terencana untuk menciptakan suasana belajar dan proses pembelajaran agar peserta didik dapat aktif dalam mengembangkan potensi diri agar memiliki kekuatan spiritual, keagamaan, pengendalian diri, kepribadian, kecerdasan, akhlak mulia, serta keterampilan yang diperlukan dirinya, masyarakat, bangsa dan negara. Tanpa adanya pendidikan, akan sulit bagi seseorang untuk dapat tumbuh selaras dengan keinginan maju dan sejahtera. Ilmu pengetahuan diperoleh dengan adanya pendidikan melalui kegiatan pembelajaran yang menjadikan manusia unggul melebihi makhluk lainnya.

Pembelajaran pada dasarnya merupakan proses komunikasi antara pendidik dengan peserta didik untuk melakukan kegiatan pembelajaran (Simamora, Hernaeny, \& Safitri, 2020). Kemampuan peserta didik dalam belajar matematika dapat dilihat dari tiga aspek, yaitu pemahaman konsep, komunikasi dan pemecahan masalah (Masykur, Nofrizal, \& Syazali, 2017). Kemampuan pemahaman konsep merupakan kemampuan dalam menerjemahkan, menafsirkan serta menyimpulkan suatu konsep matematika berdasarkan pembentukan pengetahuannya sendiri, bukan sekedar menghafal sehingga mampu menjelaskan kembali konsep yang didapatkan baik dengan lisan ataupun tulisan (Rismayanti \& Pujiastuti, 2020). Pentingnya memahami konsep matematika yaitu agar memudahkan peserta didik dalam memahami masalah, merancang strategi penyelesaian serta dapat menyelesaikan masalah secara terstruktur dan sistematis (Farhan \& Zulkarnain, 2019). Oleh sebab itu dalam pembelajaran matematika, pemahaman konsep menjadi salah satu kemampuan yang harus dikuasai (Tama, Rinaldi, \& Andriani, 2018).

Terdapat beberapa peneliti terdahulu yang telah meneliti kemampuan pemahaman konsep diantaranya yaitu menggunakan model pembelajaran Probing-Promoting Learning, Think Pair Share, Project Based Learning, Teams Games Tournaments, Student Teams Achievement Division dan Generative Learning (Aufa, Zubainur, \& Munzir, 2020; Damayanti, Rinaldi, \& Putra, 2021; Dewi, Sugiarta, \& Parwati, 2021; Komarudin, Puspita, Suherman, \& Fauziyyah, 2020; Kurniati, Jannah, \& Fitraini, 2021; Septian, Agustina, \& Maghfirah, 2020; Sumarli, Kusumawati, \& Yanto, 2021). Menurut Indrawati (dalam Syazali, Iqoh, Mufty, \& Rahmawati, 2021) tingkat prestasi pembelajaran matematika peserta didik masih tergolong relatif sangat rendah dan jauh dari harapan. Persoalan yang memungkinkan masih rendahnya prestasi pembelajaran matematika peserta didik yaitu minimnya minat, motivasi dan inovasi dalam kegiatan pembelajaran (Nugroho, 2018).

Penerapan model pembelajaran yang tepat dapat menjadikan peserta didik aktif selama proses pembelajaran (Suharni, 2020). Salah satu model pembelajaran tersebut yaitu model pembelajaran WEE (Wondering Exploring Explaining) yang dirancang agar peserta didik dapat menambah pengetahuan dan berpikir aktif selama kegiatan pembelajaran (Lestiana, Aed, Hadi, \& Rosidi, 2018). Model pembelajaran WEE pada pelaksanaannya meliputi tiga tahapan, yaitu tahap Wondering, tahap Exploring dan tahap Explaining. Adapun langkah-langkah model pembelajaran WEE yaitu (1) pembentukan kelompok yang setiap anggotanya berjumlah 4-6 orang perkelompok, (2) pendidik membagi teks bacaan materi pelajaran, (3) tahap Wondering dimana peserta didik mulai muncul keingintahuaannya setelah membaca teks bacaan, (4) tahap Exploring dimana peserta didik mulai mengeksplorasi atau mencari tahu apa yang ingin diketahuinya, (5) tahap Explaining dimana peserta didik diminta untuk menjelaskan hasil eksplorasinya kepada peserta didik lain, (7) sesi tanya jawab. Terdapat peneliti terdahulu yang menerapkan model WEE sebagai pengembangan lembar kerja siswa (Lestiana et al., 2018).

Keberhasilan dalam proses pembelajaran harus didukung oleh banyak faktor, salah satu faktornya yaitu dari dalam diri atau faktor internal (Novesar, 2020). Faktor internal yaitu meliputi Curiosity (rasa ingin tahu). Rasa ingin tahu merupakan suatu sikap atau tindakan yang senantiasa berupaya untuk mengetahui dan 
mempelajari secara mendalam tentang berbagai hal yang diperoleh (Solehuzain \& Dwidayati, 2017). Rasa ingin tahu bukan hanya terhadap ilmu pengetahuan, tetapi juga terhadap hal yang lainnya. Hal tersebut menjadikan rasa ingin tahu sebagai sesuatu yang tidak mungkin lepas dari ilmu matematika (Nurkamilah, 2017). Terdapat beberapa peneliti terdahulu yang meneliti Curiosity (rasa ingin tahu) diantaranya yaitu melalui model Problem Posing dan Problem Solving, melalui model Discovery Learning, meningkatkan rasa ingin tahu mahasiswa melalui penerapan pembelajaran berbasis proyek, dan melalui model STAD dan TGT (Husni, 2014; Insani, 2018; Mardhiyana, 2017; Muldayanti, 2013).

Berdasarkan penelitian terdahulu, keterbaruan dari penelitian ini yaitu belum adanya penelitian yang meneliti tentang pengaruh model pembelajaran WEE yang ditinjau dari Curiosity. Tujuan dari penelitian ini untuk mengetahui pengaruh dari model pembelajaran WEE ditinjau dari Curiosity terhadap kemampuan pemahaman konsep matematis peserta didik. Bila terdapat pengaruh maka model pembelajaran WEE ditinjau dari Curiosity pada penelitian ini dikatakan berhasil memberikan pengaruh terhadap kemampuan pemahaman konsep matematis peserta didik.

\section{METODE}

Penelitian ini dilaksanakan di SMP Negeri 1 Bunga Mayang, tahun pelajaran 2020/2021 pada materi bangun datar segiempat. Penelitian ini termasuk jenis penelitian Quasi Eksperimental Design karena bertujuan untuk mengetahui pengaruh yang dihasilkan setelah adanya pemberian perlakuan tertentu di dalam kelas. Populasi pada penelitian ini adalah seluruh peserta didik kelas VII SMP Negeri 1 Bunga Mayang yang terdiri dari kelas VII A, VII B, VII C dan VII D. Sedangkan pengambilan sampel dilakukan menggunakan teknik Cluster Random Sampling yaitu pengambilan sampel dengan cara memilih salah satu atau beberapa kelompok secara acak dengan melakukan pengundian dan diperoleh kelas VII A, VII B dan VII C sebagai sampel pada penelitian ini. Penelitian ini menggunakan tiga kelas, dimana kelas pertama adalah kelas eksperimen 1 yang diberikan perlakuan menggunakan model pembelajaran WEE (Wondering Exploring Explaining) sebanyak 32 peserta didik, kemudian kelas kedua dan kelas ketiga sebagai kelas perbandingan, dimana kelas kedua adalah kelas eksperimen 2 yang diberikan perlakuan menggunakan model pembelajaran RTE (Rotating Trio Exchange) sebanyak 31 peserta didik dan kelas ketiga adalah kelas kontrol yang diberikan perlakuan menggunakan model pembelajaran Direct Instruction sebanyak 31 peserta didik

Variabel pada penelitian ini terdiri dari variabel bebas dan variabel terikat. Variabel bebas (Independent Variable) yaitu model pembelajaran WEE (Wondering Exploring Explaining) sebagai $\mathrm{X}_{1}$ dan Curiosity sebagai $\mathrm{X}_{2}$ sedangkan variabel terikat (Dependent Variable) yaitu kemampuan pemahaman konsep matematis sebagai (Y). Teknik pengumpulan data pada penelitian ini menggunakan tes, angket dan dokumentasi. Adapun tes yang dilakukan adalah tes akhir (posttest) berupa essay sebanyak 8 soal yang telah diuji validitasnya, kemudian angket Curiosity berupa 18 pernyataan yang memuat item positif dan negatif dan dokumentasi berupa foto serta video saat pembelajaran. Uji coba instrumen yang dilakukan adalah uji validitas, uji reliabilitas, uji tingkat kesukaran dan uji daya pembeda untuk soal tes sedangkan untuk angket hanya dilakukan uji validitas dan reliabilitas saja. Uji prasyarat yang digunakan yaitu uji normalitas dan uji homogenitas. Pengujian hipotesis menggunakan uji anova (Analysis of Variance) dua arah sel tak sama dan dilanjutkan dengan uji lanjut setelah anova menggunakan metode Scheffe.

\section{HASIL}

Hasil dari penelitian ini berupa deskripsi data tes kemampuan pemahaman konsep matematis dan angket Curiosity peserta didik, dimana pada kelas eksperimen 1 menggunakan model pembelajaran WEE (Wondering Exploring Explaining), kelas eksperimen 2 menggunakan model pembelajaran RTE (Rotating 
Trio Exchange) dan kelas kontrol menggunakan model pembelajaran Direct Instruction. Berikut ini disajikan Tabel hasil posttest kemampuan pemahaman konsep matematis dan angket Curiosity:

Tabel 1. Deskripsi Data Hasil Posttest Kemampuan Pemahaman Konsep Matematis

\begin{tabular}{lccccccc}
\hline Kelas & $X_{\text {maks }}$ & $X_{\min }$ & $\bar{X}$ & $M_{e}$ & $M_{o}$ & $R$ & $S D$ \\
\hline Eksperimen 1 & 91 & 44 & 72,19 & 73,50 & 62 & 47 & 12,965 \\
Eksperimen 2 & 81 & 28 & 65,94 & 66,00 & 78 & 53 & 12,220 \\
Kontrol & 78 & 10 & 52,48 & 53,00 & 78 & 68 & 17,593 \\
\hline
\end{tabular}

Sumber: diolah dari data penelitian, 2021

Berdasarkan Tabel 1., dapat disimpulkan bahwa hasil posttest kemampuan pemahaman konsep matematis peserta didik pada kelas eksperimen 1 lebih tinggi dibandingkan dengan kelas eksperimen 2 dan kelas kontrol dilihat dari nilai tertinggi $\left(X_{m a k s}\right)$, nilai terendah $\left(X_{\min }\right)$, rata-rata $(\bar{X})$ dan median $\left(M_{e}\right)$.

Tabel 2. Deskripsi Data Hasil Curiosity Peserta Didik

\begin{tabular}{lccccc}
\hline \multirow{2}{*}{ Kelas } & $\bar{X}$ & \multirow{2}{*}{ SD } & \multicolumn{3}{c}{ Kategori } \\
& & & Tinggi & Sedang & Rendah \\
\hline Eksperimen 1 & 67,313 & 4,185 & 14 & 15 & 3 \\
Eksperimen 2 & 60,548 & 5,655 & 9 & 16 & 6 \\
Kontrol & 58,387 & 6,892 & 7 & 17 & 7 \\
\hline
\end{tabular}

Sumber: diolah dari data penelitian, 2021

Berdasarkan Tabel 2., terlihat bahwa perolehan nilai rata-rata Curiosity $(\bar{X})$ pada kelas eksperimen 1 lebih tinggi dibandingkan dengan kelas eksperimen 2 dan kelas kontrol. Selanjutnya dilakukan uji prasyarat yaitu uji normalitas dan uji homogenitas. Perhitungan uji normalitas yang digunakan yaitu uji onekolmogorov-smirnov berbantuan SPSS 26 dengan taraf signifikasi $\alpha=0,05$. Apabila $p$-value $\geq 0,05$ maka data berdistribusi normal (Rinaldi, Novalia, \& Syazali, 2021). Berikut disajikan Tabel 3. yang merupakan hasil perhitungan uji normalitas.

Tabel 3. Hasil Uji Normalitas Kemampuan Pemahaman Konsep Matematis

\begin{tabular}{lccc}
\hline Kelas & $p$-value & Signifikasi & Keputusan \\
\hline Eksperimen 1 & 0,200 & 0,05 & Berdistribusi Normal \\
Eksperimen 2 & 0,200 & 0,05 & Berdistribusi Normal \\
Kontrol & 0,200 & 0,05 & Berdistribusi Normal \\
\hline \multicolumn{2}{l}{ Sumber: diolah dari data penelitian, 2021 }
\end{tabular}

Berdasarkan Tabel 3, hasil perhitungan uji normalitas diperoleh p-value pada kelas eksperimen 1, kelas eksperimen 2 dan kelas kontrol yaitu sebesar 0,200 sehingga $H_{0}$ diterima dan populasi berdistribusi normal karena $p$-value $>\alpha$. Selanjutnya perhitungan uji homogenitas posttest yaitu uji homogeneity of variances dengan berbantuan SPSS 26 disajikan dalam Tabel 4.

Tabel 4. Hasil Uji Homogenitas Kemampuan Pemahaman Konsep Matematis

\begin{tabular}{lc}
\hline Statistika & Kemampuan Pemahaman Konsep Matematis \\
\hline$p$-value & 0,332 \\
Homogenity & $p$-value $>0,05$ \\
Kesimpulan & Homogen \\
\hline Sumber: diolah dari data penelitian, 2021
\end{tabular}


Berdasarkan Tabel 4, terlihat hasil kemampuan pemahaman konsep matematis berasal dari varians populasi yang sama atau homogen karena sesuai dengan kriteria dimana $p$-value $>\alpha$. Selanjutnya disajikan Tabel 5. merupakan hasil normalitas angket Curiosity.

Tabel 5. Hasil Uji Normalitas Angket Curiosity

\begin{tabular}{lccc}
\hline Kelas & $L_{\text {hitung }}$ & $L_{\text {tabel }}$ & Keputusan \\
\hline Eksperimen 1 & 0,131 & 0,157 & Berdistribusi Normal \\
Eksperimen 2 & 0,135 & 0,159 & Berdistribusi Normal \\
Kontrol & 0,157 & 0,159 & Berdistribusi Normal \\
\hline
\end{tabular}

Sumber: diolah dari data penelitian, 2021

Berdasarkan Tabel 5., hasil uji normalitas angket Curiosity menunjukkan bahwa $L_{\text {hitung }}<L_{\text {tabel }}$ sehingga $H_{0}$ diterima atau sampel berasal dari populasi yang berdistribusi normal. Selanjutnya dilakukan uji homogenitas angket Curiosity dapat dilihat dalam Tabel 6.

Tabel 6. Hasil Uji Homogenitas Angket Curiosity

\begin{tabular}{lc}
\hline Statistika & Kemampuan Pemahaman Konsep Matematis \\
\hline$\chi^{2}{ }_{\text {hitung }}$ & 4,804 \\
$\chi_{\text {tabel }}$ & 5,991 \\
Kesimpulan & Homogen \\
\hline
\end{tabular}

Sumber: diolah dari data penelitian, 2021

Berdasarkan Tabel 6., terlihat data angket Curiosity berasal dari varians yang sama atau homogen karena $\chi^{2}$ hitung $<\chi_{\text {tabel. }}^{2}$ Setelah diketahui data pada penelitian ini berdistribusi normal dan homogen, maka selajutnya yaitu uji hipotesis. Uji hipotesis pada penelitian ini menggunakan uji anova (Analysis of Variance) dua arah sel tak sama dengan berbantuan SPSS 26. Hasil uji anova pada penelitian ini disajikan dalam Tabel 7.

Tabel 7. Hasil Uji Anova Dua Arah Sel Tak Sama

\begin{tabular}{llcc}
\hline Hipotesis Anova & Kemampuan & $p$-value & Keputusan \\
\hline Model & Pemahaman & 0,000 & $H_{0 A}$ ditolak \\
Curiosity & Konsep & 0,000 & $H_{0 B}$ ditolak \\
Model*Curiosity & Matematis & 0,573 & $H_{0 A B}$ diterima \\
\hline
\end{tabular}

Sumber: diolah dari data penelitian, 2021

Berdasarkan Tabel 7., diperoleh hasil perhitungan anova dua arah sel tak sama yaitu hipotesis pertama $H_{0 A}$ ditolak, karena $p$-value $<0,05$. Hipotesis kedua $H_{0 B}$ ditolak, karena $p$-value $<0,05$. Hipotesis ketiga $H_{0 A B}$ diterima, karena $p$-value $>0,05$. Setelah dilakukan uji anova dua arah sel tak sama, maka selanjutnya dilakukan uji komparasi ganda menggunakan metode Scheffe dengan berbantuan SPSS 26 yang disajikan pada Tabel 8. 
Tabel 8. Hasil Analisis Komparasi Ganda

\begin{tabular}{lcc}
\hline (I) Curiosity & (J) Curiosity & $p$-value \\
\hline Tinggi & Sedang & 0,037 \\
& Rendah & 0,000 \\
Sedang & Tinggi & 0,037 \\
& Rendah & 0,000 \\
Rendah & Tinggi & 0,000 \\
& Sedang & 0,000 \\
\hline
\end{tabular}

Sumber: diolah dari data penelitian, 2021

Berdasarkan Tabel 8., hasil analisis komparasi ganda yaitu pada $H_{0}: \beta_{1} \neq \beta_{2}$ ditolak, karena $p$-value $<0,05$ kemudian pada $H_{0}: \beta_{1} \neq \beta_{3}$ ditolak, karena $p$-value $<0,05$ dan pada $H_{0}: \beta_{2} \neq \beta_{3}$ ditolak, karena $p$ value $<0,05$.

\section{PEMBAHASAN}

Penelitian ini dilaksanakan di SMP Negeri 1 Bunga Mayang, dimulai pada tanggal 5 April 2021. Penelitian ini mempunyai dua variabel bebas yaitu model pembelajaran Wondering Exploring Explaining (WEE) dan Curiosity, serta satu variabel terikat yaitu kemampuan pemahaman konsep matematis peserta didik. Populasi pada penelitian ini adalah seluruh peserta didik kelas VII SMP Negeri 1 Bunga Mayang. Sampel pada penelitian ini adalah kelas VII A sebagai kelas eksperimen 1 yang diberi perlakuan menggunakan model pembelajaran WEE (Wondering Exploring Explaining), kemudian kelas VII B sebagai kelas eksperimen 2 yang diberi perlakuan menggunakan model pembelajaran RTE (Rotating Trio Exchange) dan kelas VII C sebagai kelas kontrol yang diberi perlakuan menggunakan model Direct Instruction. Peserta didik pada kelas VII A yaitu berjumlah 32 peserta didik, sedangkan kelas VII B dan VII C masing-masing berjumlah 31 peserta didik, sehingga jumlah sampel keseluruhan yaitu 94 peserta didik.

Pembelajaran menggunakan model WEE (Wondering Exploring Explaining) ini pada pelaksanaanya yaitu peserta didik dilatih untuk menambah pengetahuannya melalui kegiatan membaca dan terlihat peserta didik lebih aktif pada saat berdiskusi mencari jawaban dari permasalahan-permasalahan yang mereka temukan. Meskipun pada awal pembelajaran terdapat beberapa peserta didik yang kurang percaya diri, akan tetapi proses pembelajaran berjalan dengan baik. Peserta didik juga mampu menjawab soal-soal latihan yang ada pada LKPD dengan baik. Model pembelajaran WEE (Wondering Exploring Explaining) ini pada pelaksanaannya meliputi tiga tahapan, yaitu tahap Wondering (bertanya-tanya) dimana pada tahap ini peserta didik mulai muncul keingintahuannya terhadap materi pelajaran setelah membaca, kemudian tahap Exploring (menjelajahi) dimana pada tahap ini peserta didik mulai mencari jawaban tentang apa yang ingin diketahuinya dan tahap Explaining (menjelaskan) dimana peserta didik mulai menjelaskan hasil eksplorasinya kepada peserta didik yang lain. Gambar 1. merupakan hasil dokumentasi menggunakan model pembelajaran WEE. 


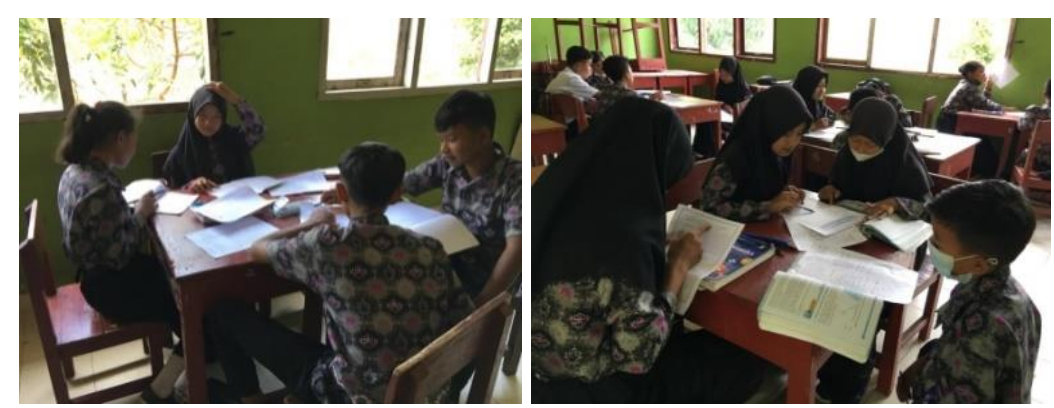

Gambar 1. Pembelajaran menggunakan model WEE

Terdapat beberapa kelebihan pada saat pelaksanaan model WEE yaitu (1) dapat menggali pengetahuan awal yang dimiliki oleh peserta didik, (2) peserta didik berperan aktif dalam memahami konsep matematika, (3) menciptakan rasa tanggung jawab kerja sama antar kelompok, (4) melatih daya pikir peserta didik dalam mencari tahu apa yang ingin diketahuinya, (5) menanamkan kebiasaan literasi mengenai materi pelajaran dan (6) mendorong peserta didik agar dapat menambah rasa percaya diri pada saat tahap Explaining. Selain itu terdapat pula beberapa kelemahan pada model ini diantaranya yaitu (1) keterbatasan waktu pada saat peserta didik menjelaskan hasil eksplorasinya, (2) memerlukan persiapan pada saat membuat teks bacaan yang akan diberikan kepada peserta didik dan (3) peserta didik yang memiliki kemampuan lebih unggul akan sering bekerja lebih pada saat kegiatan kelompok.

Model pembelajaran RTE (Rotating Trio Exchange) merupakan model pembelajaran berkelompok yang terdiri dari tiga anggota yang dapat bergantian pasangan dengan kelompok lain secara memutar sesuai dengan arah jarum jam atau berlawanan arah jarum jam. Pembelajaran menggunakan model RTE (Rotating Trio Exchange) ini pada penerapannya membuat peserta tidak merasa bosan karena selalu berganti anggota kelompok. Namun peserta didik sedikit kebingungan pada saat rotasi anggota kelompok sehingga suasana kelas menjadi kurang kondusif dan memakan banyak waktu. Beberapa peserta didik masih ada yang kurang terlibat secara aktif pada saat diskusi berlangsung sehingga hanya didominasi oleh salah satu orang saja di setiap kelompok. Hasil dokumentasi menggunakan model pembelajaran RTE dapat dilihat dalam Gambar 2.

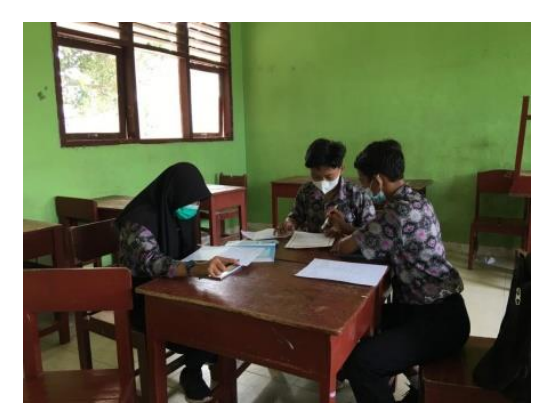

\section{Gambar 2. Pembelajaran Menggunakan Model RTE}

Kemudian pada model pembelajaran Direct Instruction atau kelas kontrol, peserta didik terlihat pasif yang hanya mengandalkan penjelasan dari pendidik saja sehingga ketika peserta didik diberikan permasalahan, masih banyak peserta didik yang merasa kesulitan untuk menyelesaikannya. Gambar 3. berikut ini merupakan hasil dokumentasi menggunakan model pembelajaran Direct Instruction. 


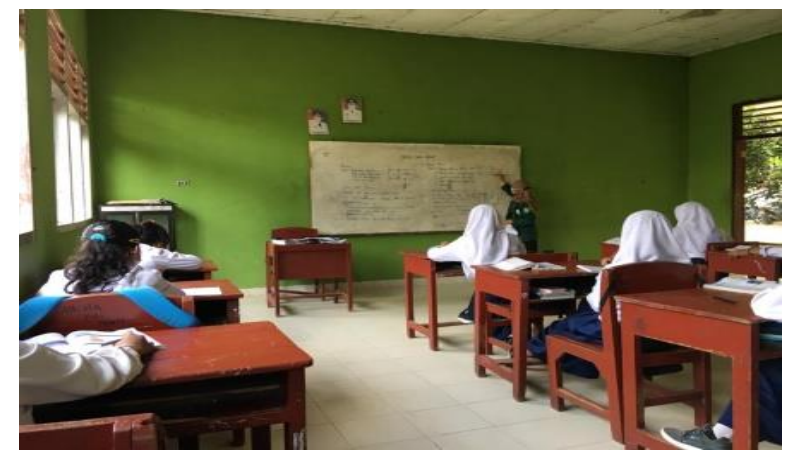

\section{Gambar 3. Pembelajaran Menggunakan Model Direct Instruction}

Selanjutnya hasil posttest kemampuan pemahaman konsep matematis peserta didik pada Tabel 1., materi bangun datar segiempat pada kelas eksperimen 1 dengan menggunakan model pembelajaran WEE (Wondering Exploring Explaining) diperoleh nilai maksimum $\left(X_{\text {maks }}\right)=91$, nilai minimum $\left(X_{\min }\right)=44$ dan nilai rata-rata $(\bar{X})=72,19$. Sedangkan pada kelas eksperimen 2 menggunakan model pembelajaran RTE (Rotating Trio Exchange) diperoleh nilai maksimum $\left(X_{\text {maks }}\right)=81$, nilai minimum $\left(X_{\text {min }}\right)=28$ dan nilai rata-rata $(\bar{X})=65,94$ dan pada kelas kontrol menggunakan model pembelajaran Direct Instruction diperoleh nilai maksimum $\left(X_{\text {maks }}\right)=78$, nilai minimum $\left(X_{\text {min }}\right)=10$ dan nilai rata-rata $(\bar{X})=52,48$. Sehingga dapat disimpulkan bahwa hasil posttest pada kelas eksperimen 1 lebih tinggi dibandingkan dengan kelas eksperimen 2 dan kelas kontrol.

Hasil angket Curiosity peserta didik pada Tabel 2, kelas eksperimen 1 menggunakan model pembelajaran WEE (Wondering Exploring Explaining) diperoleh nilai rata-rata $(\bar{X})=67,313$. Kemudian pada kelas eksperimen 2 menggunakan model pembelajaran RTE (Rotating Trio Exchange) diperoleh nilai rata-rata $(\bar{X})=60,548$ dan pada kelas kontrol menggunakan model pembelajaran Direct Instruction diperoleh nilai rata-rata $(\bar{X})=58,387$. Sehingga dapat disimpulkan hasil Curiosity peserta didik pada kelas eksperimen 1 lebih baik dibandingkan dengan kelas eksperimen 2 dan kelas kontrol.

Hasil uji normalitas kemampuan pemahaman konsep pada Tabel 3, diperoleh nilai $p$-value pada kelas eksperimen 1, kelas eksperimen 2 dan kelas kontrol sebesar 0,200 sehingga $H_{0}$ diterima dan dapat disimpulkan bahwa data yang diperoleh berasal dari populasi yang berdistribusi normal karena sesuai dengan kriteria apabila $p$-value $\geq 0,05$ maka data tersebut berdistribusi normal. Sebaliknya apabila $p$-value $<0,05$ maka data tersebut tidak berdistribusi normal. Kemudian uji homogenitas pada Tabel 4, diperoleh nilai $p$-value sebesar 0,332 sehingga data tersebut berasal dari varians yang sama atau homogen karena sesuai dengan kriteria apabila $p$-value $\geq 0,05$ maka data tersebut homogen. Sebaliknya apabila $p$-value < 0,05 maka data tersebut tidak homogen.

Hasil uji normalitas Curiosity pada Tabel 5, diperoleh pada kelas eksperimen 1 nilai $L_{\text {hitung }}=0,131$ dengan $L_{\text {tabel }}=0,157$ sehingga $L_{\text {hitung }}<L_{\text {tabel }}$. Pada kelas eksperimen 2 diperoleh nilai $L_{\text {hitung }}=0,135$ dengan $L_{\text {tabel }}=0,159$ sehingga $L_{\text {hitung }}<L_{\text {tabel }}$. Kemudian pada kelas kontrol diperoleh nilai $L_{\text {hitung }}=0,157$ dengan $L_{\text {tabel }}=0,159$ sehingga $L_{\text {hitung }}<L_{\text {tabel }}$. Dapat disimpulkan bahwa pada kelas eksperimen 1, eksperimen 2 dan kelas kontrol sehingga $H_{0}$ diterima dan sampel berasal dari populasi yang berdistribusi normal. Hasil uji homogenitas pada Tabel 6, diperoleh $\chi_{\text {hitung }}^{2}=4,804$ dan $\chi_{\text {tabel }}^{2}=5,991$ sehingga dapat disimpulkan bahwa data berasal dari varians yang sama atau homogen karena $\chi^{2}$ hitung $<\chi^{2}$ tabel.

Setelah data berdistribusi normal dan homogen maka selanjutnya dilakukan uji hipotesis anova dua jalur sel tak sama. Hasil uji anova dua jalur sel tak sama diperoleh hipotesis pertama $H_{0 A}$ ditolak, karena $p$ value $<0,05$ maka terdapat pengaruh kemampuan pemahaman konsep matematis antara peserta didik yang menggunakan model pembelajaran WEE (Wondering Exploring Explaining), model pembelajaran RTE (Rotating Trio Exchange) dan Direct Instruction. Berdasarkan pemaparan yang telah dijelaskan di atas 
bahwa model pembelajaran WEE (Wondering Exploring Explaining) memiliki nilai rata-rata yang lebih tinggi dibandingkan dengan model pembelajaran RTE (Rotating Trio Exchange) dan Direct Instruction.

Hipotesis kedua $H_{O B}$ ditolak, karena $p$-value $<0,05$ maka terdapat pengaruh kemampuan pemahaman konsep matematis antara peserta didik yang memiliki Curiosity tinggi, sedang dan rendah. Berdasarkan pemaparan di atas bahwa peserta didik yang memiliki Curiosity tinggi lebih baik dibandingkan dengan peserta didik yang memiliki Curiosity sedang dan rendah. Hipotesis ketiga $H_{O A B}$ diterima, karena $p$-value > 0,05 sehingga dapat disimpulkan bahwa tidak terdapat interaksi antara model pembelajaran WEE (Wondering Exploring Explaining) dengan Curiosity terhadap kemampuan pemahaman konsep matematis peserta didik.

Setelah dilakukan uji anova dua arah sel tak sama, maka selanjutnya adalah uji komparasi ganda dengan metode Scheffe diperoleh hasil pada $H_{0}: \beta_{1} \neq \beta_{2}$ ditolak, karena $p$-value $<0,05$ yang berarti terdapat perbedaan yang signifikan antara peserta didik yang memiliki curiosity sedang dan peserta didik yang memiliki curiosity rendah. Peserta didik yang memiliki nilai rata-rata curiosity sedang lebih baik dibandingkan dengan peserta didik yang memiliki curiosity rendah. Sehingga dapat disimpulkan bahwa kemampuan pemahaman konsep matematis dengan curiosity sedang lebih baik dibandingkan dengan curiosity rendah.

Selanjutnya $H_{0}: \beta_{1} \neq \beta_{3}$ ditolak, karena $p$-value $<0,05$ yang berarti terdapat perbedaan yang signifikan antara peserta didik yang memiliki curiosity tinggi dan peserta didik yang memiliki curiosity rendah. Peserta didik yang memiliki nilai rata-rata curiosity tinggi lebih baik dibandingkan dengan peserta didik yang memiliki curiosity rendah. Sehingga dapat disimpulkan bahwa kemampuan pemahaman konsep matematis dengan curiosity tinggi lebih baik dibandingkan dengan curiosity rendah.

Kemudian $H_{0}: \beta_{2} \neq \beta_{3}$ ditolak, karena $p$-value $<0,05$ yang berarti terdapat perbedaan yang signifikan antara peserta didik yang memiliki curiosity tinggi dan peserta didik yang memiliki curiosity sedang. Peserta didik yang memiliki nilai rata-rata curiosity tinggi lebih baik dibandingkan dengan peserta didik yang memiliki curiosity sedang. Sehingga dapat disimpulkan bahwa kemampuan pemahaman konsep matematis dengan curiosity tinggi lebih baik dibandingkan dengan curiosity sedang.

Berdasarkan pemaparan di atas, dapat ditarik kesimpulan bahwa pembelajaran dengan menggunakan model WEE (Wondering Exploring Explaining) lebih efektif digunakan untuk kemampuan pemahaman konsep matematis. Proses pembelajaran pada model WEE (Wondering Exploring Explaining) ini juga memberikan pengaruh yang baik bagi peserta didik. Peserta didik terlihat aktif, kondusif dan melakukan komunikasi dengan baik karena pada saat pembelajaran terdapat diskusi kelompok yang berarti peserta didik dapat bertukar pikiran dengan anggota kelompoknya. Hal ini sejalan dengan hasil dari penelitian yang dilakukan oleh Tri Wahyuni yaitu menunjukkan bahwa kemampuan pemahaman konsep matematis peserta didik melalui model WEE dengan strategi QSH ternyata lebih baik dan efektif dibandingkan dengan peserta didik yang menggunakan model pembelajaran konvensional (Wahyuni, Anggoro, \& Komarudin, 2019). Pembelajaran menggunakan model WEE juga mampu memaksimalkan kemampuan pemahaman konsep matematis peserta didik. Letak relevansi penelitian ini dengan penelitian Tri Wahyuni yaitu sama-sama menerapkan model pembelajaran WEE untuk meningkatkan kemampuan pemahaman konsep matematis peserta didik, sedangkan perbedannya yaitu dalam penelitian Tri Wahyuni tidak ditinjau dari Curiosity. Ketidakmaksimalan pada saat penerapan model ini yaitu alokasi waktu yang terbatas sehingga pada saat tahap Wondering ketika peserta didik membaca teks bacaan, waktu yang diberikan lebih ringkas. 


\section{SIMPULAN}

Berdasarkan hasil analisis data dan pengujian hipotesis yang telah dilakukan, maka dapat disimpulkan bahwa model pembelajaran WEE (Wondering Exploring Explaining) lebih efektif dibandingkan dengan model pembelajaran RTE (Rotating Trio Exchange) dan Direct Instruction terhadap kemampuan pemahaman konsep matematis peserta didik. Terdapat perbedaan curiosity tinggi, sedang dan rendah terhadap kemampuan pemahaman konsep matematis peserta didik. Namun tidak terdapat interaksi antara model pembelajaran WEE (Wondering Exploring Explaining) dengan Curiosity terhadap kemampuan pemahaman konsep matematis peserta didik.

\section{UCAPAN TERIMAKASIH}

Penulis ingin mengucapkan terimakasih kepada kepala sekolah dan seluruh guru di SMP Negeri 1 Bunga Mayang yang telah membantu penulis selama pelaksanaan penelitian. Tidak lupa juga penulis mengucapkan terimakasih kepada Bapak Dr. Achi Rinaldi, M.Si. selaku dosen pembimbing 1 dan Bapak Rizki Wahyu Yunian Putra, M.Pd. selaku pembimbing 2 yang telah membimbing penulis sehingga artikel ini dapat terselesaikan.

\section{DAFTAR RUJUKAN}

Aufa, N., Zubainur, C. M., \& Munzir, S. (2020). Pengembangan Perangkat Pembelajaran Model Missouri Mathematics Project (MMP) Berbantuan Software Geogebra untuk Meningkatkan Pemahaman Konsep Siswa. Jurnal Inovasi Penelitian, 1(3), 1-4.

Damayanti, I., Rinaldi, A., \& Putra, R. W. Y. (2021). Probing-Promting Learning Berbantuan Bahan Ajar Desain Didaktis: Dampaknya Terhadap Pemahaman Konsep. Jurnal Pendidikan Matematika, 5, 4653.

Dewi, N. K. T. Y., Sugiarta, I. M., \& Parwati, N. N. (2021). Implementasi Model Pembelajaran Kooperatif Tipe Think Pair Share (TPS) Berbantuan Alat Peraga untuk Meningkatkan Pemahaman Konsep Matematika Siswa. Journal of Education Action Research, 5(1), 40-47. https://doi.org/10.23887/jear.v5i1.31789

Farhan, M., \& Zulkarnain, I. (2019). Analisis Kesalahan Mahasiswa pada Mata Kuliah Kalkulus Peubah Banyak Berdasarkan Newmann's Error Analisis. JKPM (Jurnal Kajian Pendidikan Matematika), 4(2), 121. https://doi.org/10.30998/jkpm.v4i2.3843

Husni, M. A. (2014). Keefektifan Pembelajaran Matematika dengan Problem Posing dan Problem Solving Ditinjau dari Prestasi dan Curiosity. PYTHAGORAS : Jurnal Pendidikan Matematika, 9(1), 11-21.

Indonesia, R. (2003). Undang-undang Republik Indonesia Nomor 20 Tahun 2003 Tentang Sistem Pendidikan Nasional. In Jakarta: BP Panca Usaha. https://doi.org/10.1111/j.16512227.1982.tb08455.x

Insani, S. U. (2018). Upaya Meningkatkan Rasa Ingin Tahu Siswa Terhadap Pembelajaran Matematika Melalui Model Discovery Learning dengan Pendekatan Saintifik pada Siswa Kelas X MIA 2 MAN Yogyakarta 1. Jurnal Pendidikan Tambusai, 2(5), 1161-1171.

Komarudin, K., Puspita, L., Suherman, S., \& Fauziyyah, I. (2020). Analisis Pemahaman Konsep Matematis Peserta Didik Sekolah Dasar: Dampak Model Project Based Learning Model. DIDAKTIKA TAUHIDI: Jurnal Pendidikan Guru Sekolah Dasar, 7(1), 43. https://doi.org/10.30997/dt.v7i1.1898

Kurniati, A., Jannah, N., \& Fitraini, D. (2021). Pengaruh Penerapan Model Pembelajaran Kooperatif Tipe 
Talking Stick terhadap Pemahaman Konsep Matematis Siswa. Juring (Journal for Research in Mathematics Learning), 4(1), 51-62. Retrieved http://jurnal.fkip.unila.ac.id/index.php/MTK/article/view/777

Lestiana, I., Aed, M., Hadi, W. P., \& Rosidi, I. (2018). Pengembangan Lembar Kerja Siswa (LKS) Berbasis Wondering Exploring Explaining (WEE) Science pada Materi Struktur Bumi dan Dinamikanya. Konstruktivisme, 10(1), 113-129.

Mardhiyana, D. (2017). Upaya Meningkatkan Rasa Ingin Tahu Mahasiswa Melalui Penerapan Pembelajaran Berbasis Proyek pada Mata Kuliah Evaluasi Proses dan Hasil Pembelajaran Matematika. Jurnal Ilmiah Pendidikan Matematika, 5(1), 1-8.

Masykur, R., Nofrizal, N., \& Syazali, M. (2017). Pengembangan Media Pembelajaran Matematika dengan Macromedia Flash. Al-Jabar : Jurnal Pendidikan Matematika, 8(2), 177.

Muldayanti, N. D. (2013). Pembelajaran Biologi Model STAD dan TGT ditinjau dari Keingintahuan dan Minat Belajar Siswa. Jurnal Pendidikan IPA Indonesia, 2(1), 12-17.

Novesar, M. R. (2020). Students Emotional Intelligence as Catalisator for Academic Achievement. Management Sustainable Development Journal, 2(2), 53-68. https://doi.org/10.46229/msdj.v2i2.188

Nugroho, H. M. (2018). Penerapan Model Pembelajaran Realistic Mathematics Education (RME) untuk Meningkatkan Motivasi dan Prestasi Belajar Matematika Materi Statistika pada Peserta Didik Kelas XI TP3RP SMK Negeri 1 Kendal Tahun Pelajaran 2015/2016. Journal of Medives : Journal of Mathematics Education IKIP Veteran Semarang, 2(2), 213. https://doi.org/10.31331/medives.v2i2.620

Nurkamilah, M. (2017). Upaya Meningkatkan Keingintahuan Matematis Siswa Menggunakan Guided Discovery Learning Setting Kolaboratif. Jurnal THEOREMS (The Original Research of Mathematics), 1(2), 51-63.

Rinaldi, A., Novalia, S. P., \& Syazali, M. (2021). Statistika Inferensial untuk Ilmu Sosial dan Pendidikan. PT Penerbit IPB Press.

Rismayanti, T. A., \& Pujiastuti, H. (2020). Pengaruh Model Search Solve Create Share (SSCS) terhadap Kemampuan Pemahaman Konsep Matematis. JKPM (Jurnal Kajian Pendidikan Matematika), 5(2), 183. https://doi.org/10.30998/jkpm.v5i2.6345

Septian, A., Agustina, D., \& Maghfirah, D. (2020). Model Pembelajaran Kooperatif Tipe Student Teams Achievement Division (STAD) untuk Meningkatkan Pemahaman Konsep Matematika. Mathema: Jurnal Pendidikan Matematika, 2(2), 10. https://doi.org/10.33365/jm.v2i2.652

Simamora, L., Hernaeny, U., \& Safitri, N. D. (2020). Pengaruh Model Pembelajaran Attention, Relevance, Confidence, Satisfaction (ARCS) terhadap Kemampuan Pemecahan Masalah Matematika. JKPM (Jurnal Kajian Pendidikan Matematika), 5(2), 245. https://doi.org/10.30998/jkpm.v5i2.6405

Solehuzain, \& Dwidayati, N. K. (2017). Kemampuan Berpikir Kreatif dan Rasa Ingin Tahu pada Model Problem-Based Learning dengan Masalah Open Ended. Unnes Journal of Mathematics Education Research, 6(1), 103-111.

Suharni. (2020). Meningkatkan Keaktifan dan Hasil Belajar Melalui Penerapan Model Pembelajaran Wide Game pada Peserta Didik Kelas VIID SMP Negeri 13 Tegal. Jurnal Paedagogy: Jurnal Penelitian Dan Pengembangan Pendidikan, 7(4), 281-288.

Sumarli, Kusumawati, I., \& Yanto, T. (2021). Pengaruh Model Generative Learning (GL) terhadap Pemahaman Konsep Siswa pada Materi Kinematika. Variabel, 4(1), 9-14.

Syazali, M., Iqoh, U., Mufty, V. F., \& Rahmawati, Y. (2021). Auditory intellectually repetition learning model and trade a problem learning model on row and series algebraic material: The influences on numerical skills. Journal of Physics: Conference Series, 1796(1). https://doi.org/10.1088/17426596/1796/1/012104

Tama, A. M., Rinaldi, A., \& Andriani, S. (2018). Pemahaman Konsep Peserta Didik dengan Menggunakan 
278 Iqoh, Rinaldi, \& Putra

Graded Response Models (GRM). Desimal: Jurnal Matematika, 1(1), 91. https://doi.org/10.24042/djm.v1i1.2041

Wahyuni, T., Anggoro, B. S., \& Komarudin. (2019). Pemahaman Konsep Matematis Melalui Model WEE Dengan Strategi QSH Ditinjau Dari Self Regulation. Aksioma Jurnal Program Studi Pendidikan Matematika, 8(1), 65-72. 